\title{
Estudo de Recepção e Ergologia: novos desafios teórico-metodológicos
}

\section{Roseli Figaro}

\section{Resumo}

Este artigo discute os avanços teórico-metodológicos das pesquisas de comunicação e trabalho a partir dos estudos de recepção. Discute também a necessidade de se aprofundar as pesquisas desenvolvidas até aqui, tomando como problema a subjetividade e as relações de comunicação. Para tal, propõe-se a discutir, de maneira introdutória, as contribuições que se podem alcançar com o aporte teórico pluridisciplinar da Ergologia. A Ergologia estuda o trabalho como atividade humana que comporta prescrição de normas e re-normalização por meio do trabalho real. As relações de comunicação têm papel determinante na efetivação da atividade de trabalho.

\section{Palavras-chave}

Estudo de recepção. Mundo do trabalho. Ergologia. Discurso. Comunicação.

\section{Roseli Figaro | figaro@uol.com.br}

Universidade de São Paulo. Professora Doutora no Departamento de Comunciações e Artes da ECA-USP. Coordenadora do Grupo de Pesquisa Comunicação e Trabalho: pesquisadora do Núcleo de Pesquisa Comunicação e Censura da USP.

\section{Introdução}

Desde 0 final da década de noventa, as pesquisas sobre comunicação e trabalho têm demonstrado como a comunicação contribui para destacar a centralidade da categoria trabalho na sociedade contemporânea. A maior proximidade entre comunicação e trabalho tem sido motivada, sobretudo, pelas mudanças produzidas pela introdução de novas tecnologias de informação e pela incorporação dos processos comunicativos na gestão de recursos humanos envolvidos na reestruturação produtiva.

Do ponto de vista da episteme, este debate está inserido no campo da Comunicação e desenvolvese tendo como referencial teórico-metodológico os Estudos de Recepção e a Análise do Discurso. Os estudos sociológicos sobre trabalho (ANTUNES, 2000) e globalização (IANNI, 2003) permitiram-nos compreender a dimensão e a importância do tema para as Ciências Sociais. As pesquisas que têm como aporte os Estudos de Recepção já demonstraram a complexidade 
do processo de comunicação, afastando aquela compreensão limitada focada apenas na transmissão da informação. Os resultados amealhados pelas pesquisas de recepção, desde 0 final dos anos de 1980, comprovaram a efetividade do cruzamento de procedimentos metodológicos quantitativos e qualitativos; a produtividade dos resultados ao se comporem equipes de pesquisa multidisciplinares, bem como contribuíram com a formação de uma corrente latino-americana de pesquisas em comunicação.

Alguns conceitos ficaram marcados pelo campo da comunicação a partir dos Estudos de Recepção. Os conceitos de hegemonia, práticas culturais, mediações, circularidade e circulação são mobilizados com frequência pelos pesquisadores para explicar como os produtos culturais são apropriados pelo conjunto da sociedade. 0 conceito de subjetividade tem sido uma questão problema à medida que sua compreensão transita do assujeitamento e passividade à total autonomia do sujeito na ressignificação das mensagens. Aspecto que denota certa fragilidade tanto do arcabouço teórico quanto dos aparatos metodológicos mobilizados em proveito da pesquisa de recepção. 0s métodos qualitativos de pesquisa empírica são da preferência dos investigadores. A Análise do Discurso e a Etnografia são os métodos mais recorrentes de coleta, observação e análise do material empírico. Fator positivo diz respeito à composição das equipes multidisciplinares de pesquisadores, permitindo dar ao material empírico o tratamento à altura de sua complexidade. Exemplo de pesquisa exploratória de recepção, com equipe multidisciplinar, está registrado no livro Vivendo com a telenovela (2002), das autoras Maria Immacolata Vassalo de Lopes, Sílvia Simões Borelli e Vera da Rocha Resende.

\section{Uma abordagem teórico-metodológica para os estudos de recepção}

Em nossas pesquisas, priorizamos o conceito de mediações, entendendo-o como locus onde se dão as relações de comunicação. Isto significa dizer que abandonamos completamente a ideia de fluxo direto de um emissor/canal para um receptor. Adotamos o pressuposto de que é no lugar das relações sociais dos sujeitos enunciadores/ enunciatários que se dá a comunicação, ou seja, em que os sentidos são estabelecidos (mesmo que precária e temporariamente). Nesta proposta teórico-metodológica não se privilegia o estudo de um veículo de comunicação ou de um produto cultural. Buscamos conhecer os sujeitos no ambiente privilegiado das mediações culturais que colaboram, somadas ao repertório pessoal, para a efetivação da comunicação. Tal abordagem teórica dos Estudos de Recepção requer do ponto de vista metodológico que se estabeleça qual é o locus privilegiado das mediações.

Em nosso caso, as pesquisas, às quais nos dedicamos desde o início dos anos de 1990, indicaram o mundo do trabalho como este locus 
privilegiado. A partir de então, passamos a priorizá-lo como ambiente complexo onde se dão as relações mais conflituosas do ponto de vista da estrutura da sociedade de classes e do ponto de vista da tomada de posição social do sujeito. No que diz respeito à adequação metodológica, ao priorizar o mundo do trabalho como mediação principal no processo de recepção, fomos levados a construir um modelo com métodos quantitativos e qualitativos, sempre tendo como foco central da pesquisa os sujeitos no mundo do trabalho.

Como não partimos de um veículo de comunicação e nem de um produto cultural específicos para verificar a recepção deles pelos sujeitos, construímos um modelo que utiliza 0 método quantitativo do questionário fechado de múltipla escolha para colher dados sobre 0 perfil socioeconômico e cultural de uma amostra expressiva de sujeitos de um determinado local de trabalho (empresa). Com os dados analisados, construímos um mapa do perfil socioeconômico e cultural dos sujeitos receptores no mundo do trabalho. Com este mapa, temos condições de conhecer os hábitos de consumo cultural dos mesmos. Só a partir desse momento, vamos aos veículos e aos produtos culturais de maior relevância de consumo dos receptores da amostra estudada, aos quais passamos a acompanhar por um determinado período de tempo.

Paralelamente, selecionamos um recorte menor de receptores da amostra inicial a que será aplicado o método qualitativo da entrevista em profundidade, com o roteiro de questões abertas.
Na fase quantitativa, processamos os dados e os analisamos por meio de gráficos com cruzamento de dados do perfil socioeconômico aos dados do perfil de consumo cultural. Na fase qualitativa, transcrevemos as entrevistas e procedemos à análise dos discursos, tendo como linha teórica os aportes da Análise do Discurso francesa, relidas a partir das contribuições de M. Bakhtin. Ao mesmo tempo, procedemos à Análise do Discurso dos produtos culturais que fazem parte dos hábitos de consumo dos receptores pesquisados, os quais acompanhamos durante certo período.

Essa construção teórico-metodológica nos permitiu realizar dois grandes estudos de recepção. Um, publicado em 2001, cujo objeto de estudo é a recepção de trabalhadores metalúrgicos de uma grande montadora de veículos. Outro foi o estudo comparativo entre os trabalhadores receptores de duas grandes empresas: uma de tecnologias de comunicação e outra de telecomunicação, publicado em 2008.

\section{Desafios trazidos pelas pesquisas}

Essas pesquisas nos desafiaram com três eixos de reflexão. 0 primeiro diz respeito à abordagem da Recepção (MARTíN-BARBERO, 1993; OROZCO-GOMEZ, 1990; 1997; LOPES, BORELLI; RESENDE, 2002; ESCOTEGUY; JACKS, 2005) como viabilidade teórico-metodológica de estudo da Comunicação e das transformações no mundo do trabalho. Este eixo foi desenvolvido tomando-se como linhas de discussão as novas tecnologias, a reestruturação produtiva, a 
produção flexível e a comunicação no mundo do trabalho (FIGAR0, 2008). 0 segundo eixo trata da linguagem verbal e dos conceitos de ação comunicativa e razão comunicativa (HABERMAS,1999). 0 terceiro discute como os conceitos habermasianos têm sido utilizados em favor de um aparato discursivo que visa a dissimular as profundas contradições que se vive no mundo do trabalho (ARAGÃO, 1997; FIGAR0, 2004; 2005a; 2005b; 2008).

Sobre este terceiro eixo, vale retomar uma questão que para nós é fundamental, pois reveladora de estratégias de persuasão muito utilizadas no mundo do trabalho. Aquelas baseadas nos conceitos habermasianos de ação comunicativa e razão comunicativa. Esses conceitos, ao propugnarem a primazia da linguagem verbal em relação ao trabalho social, deixam aberto ao campo das interpretações a possibilidade de a força do discurso, de a palavra mudar por si as relações sociais, econômicas e de poder na sociedade. Exemplo de tal interpretação é o discurso difundido por manuais, revistas e compêndios de administração de empresas. Esse discurso ostenta 0 status de inovador das relações de comunicação, mas de fato dissimula 0 aumento da exploração do trabalho, o aumento da pressão e do estresse a que os trabalhadores estão submetidos. Isso pôde ser constatado por meio do acompanhamento que fizemos da comunicação corporativa das organizações que compõem 0 mundo do trabalho estudado pelas pesquisas.
Quando as relações de comunicação de fato podem revelar a recepção que os trabalhadores fazem dos sentidos do trabalho, constata-se 0 conflito, a dúvida, a pressão, o medo. As relações de comunicação no mundo do trabalho passam por mudanças efetivas, o que não significa afirmar que tais mudanças são provenientes apenas da mudança discursiva. Muito ao contrário, nossas pesquisas demonstram como a recepção da comunicação é mediada pela realidade do mundo do trabalho. A dicotomia entre linguagem verbal e trabalho, sugerida por Habermas, não explica o que se passa no processo de comunicação.

Os resultados das pesquisas de recepção que realizamos em empresas revelaram como as relações entre colegas de trabalho são importantes na comunicação entre empresas e empregados. As mediações do mundo do trabalho mostraram-se fundamentais no processo de recepção, revelando certo protagonismo do receptor no trato com as mensagens dos meios de comunicação. As explicações para tal situam-se no fato de a mensagem ser re-elaborada pelo enunciatário/ enunciador, sendo provocadora a questão de se compreender como o refazer, ou melhor, o fazer a partir de um novo ponto de vista, não é restrito aos conteúdos dos meios de comunicação e aos discursos das empresas. Tal atividade re-elaboradora coloca-se como um fato a ser compreendido. Estudá-lo, no campo da Comunicação, apresenta-se como um 
desafio que começa a se tornar mais objetivo à medida que nos aproximamos dos aportes pluridisciplinares da Ergologia.

Nesse sentido, os avanços que conseguimos com as pesquisas nos fazem apontar para dois problemas que necessitam ser mais bem compreendidos. 0 primeiro diz respeito à subjetividade do trabalhador no processo de recepção dos meios de comunicação. Provamos a importância do cotidiano do trabalho e das relações interpessoais no universo do trabalho no processo de recepção. Mas é preciso compreender melhor como tais fatores atuam no processo comunicacional. 0 segundo diz respeito às estratégias das empresas no tocante à mudança discursiva. É preciso compreender como tais estratégias são assimiladas e utilizadas pelos receptores no universo do trabalho.

São dois problemas de comunicação que, segundo nossa hipótese, só poderemos entender se aprofundarmos 0 conhecimento sobre a relação do trabalhador com seu trabalho real ${ }^{1}$ e sobre como as relações de comunicação atuam no desempenho da atividade real de trabalho. Tratar desses novos problemas de pesquisa requer ampliar a reflexão teóricometodológica com as contribuições que a abordagem ergológica da atividade de linguagem em situação de trabalho vem proporcionando às diferentes áreas do conhecimento.
Situamos os nossos problemas teóricos relativos aos estudos do sujeito receptor da comunicação na área das Ciências Sociais Aplicadas.

Buscamos respaldo nas contribuições de M. Bakhtin (1998) e A. Schaff (1967) que, ao tratarem da subjetividade, são bem claros ao reivindicarem para ela o status de problema a ser discutido na esfera das Ciências Sociais, sendo o discurso o material privilegiado para sua análise e compreensão. N. Fairclough (2001) também tem destacado a importância do discurso na mudança social. Contribui para esse debate ao mostrar como uma situação objetiva do cotidiano pode se revelar por meio do discurso, sem, no entanto, perdermos de vista 0 contexto mais amplo que nos remete à história. Y. Schwartz (1988) tem contribuído, a partir da abordagem ergológica, ao demonstrar como a atividade de trabalho real é sempre uma ação de renormalização do trabalho prescrito. M. Inês Rosa (2004) chama a atenção para a atividade de linguagem como aquela capaz de revelar os usos de si por si mesmo na atividade do sujeito com o trabalho real. Nesse contexto, a autora também tem demonstrado como a atividade de linguagem entre trabalhadores no local de trabalho concorre para expressar a dimensão subjetiva, a ação do sujeito em termos de não-conformismo, não-adequação às coerções das novas normas antecipadoras do trabalho prescrito, ou seja, aos novos métodos e processos de trabalho. 


\section{Ergologia e relações de comunicação}

Trata-se de aprofundarmos nossos estudos com as inovações que o referencial teórico da Ergologia possa nos trazer para aprimorarmos a compreensão sobre as relações de comunicação no mundo do trabalho.

A Ergologia ${ }^{2}$ é uma abordagem teóricometodológica pluridisciplinar desenvolvida por Yves Schwartz, filósofo, especialista em história das ciências e das tecnologias, diretor científico do Departamento de Ergologia (Ensino Pluridisciplinar de Situações de Trabalho) APST, da Universidade de Provence, França. 0 Departamento de Ergologia tem desenvolvido pesquisas em empresas como SNCF e Carrefour. Congrega um conjunto de pesquisadores professores doutores franceses, bem como estudantes de pós-graduação de diversos países. 0 Brasil tem desenvolvido parcerias com este centro de pesquisas da Universidade de Provence através de convênios de intercâmbio, por meio dos quais se têm aglutinado profissionais e pesquisadores de áreas como engenharia, ergonomia, psicologia, linguística, sociologia e educação. A área da Comunicação somente agora tem a oportunidade de estabelecer um relacionamento mais efetivo com tal linha de estudos promovida pelo Departamento de Ergologia - APST. Esse Departamento da Universidade de Provence iniciou suas atividades na década de 1980 e institucionalizou-se em 1998. Está voltado para a pesquisa e 0 ensino das dimensões transversais das múltiplas situações de trabalho, com ênfase no trabalho real e na dimensão subjetiva no trabalho.

A abordagem ergológica propõe um novo tratamento ao estudo da situação de trabalho. Desloca 0 interesse da tarefa para o sujeito que a realiza, na perspectiva de dar à atividade de trabalho a importância que de fato tem. $\mathrm{Ou}$ seja, a atividade de trabalho é o encontro entre trabalho prescrito (normas antecipadoras do trabalho) e experiência (particular, específica de cada sujeito). As relações de comunicação e a atividade de linguagem no mundo do trabalho são os elementos fundamentais por meio dos quais se pode entender o sistema de valores e a experiência que conformam o "saber fazer" dos trabalhadores.

A subjetividade resulta da atividade humana (ergológica), capaz de produzir e reproduzir de forma criativa. 0 fazer sempre renovado da atividade ergológica, nem sempre consciente e crítico, mas cognitivo e relativo à experiência e à

Segundo explicações de Yves Schwartz: "Ergologia vem do grego ergazein, ergasesthai que é o verbo mais genérico ou geral, diria o mais neutro, para dizer fazer alguma coisa, desempenhar bem uma ação ou uma produção. Ergon é a ação e a obra ou 0 conjunto de ações consecutivas ao fazer. Estas palavras do vocabulário da ação, do fazer são as menos marcadas pelas definições filosóficas, contrariamente ao que se dá com ação, produção, práxis, prática. É por isto que ergologia me parece ser o termo menos problemático para designar o que nós entendemos por atividade humana, termo que necessita ser redefinido, retrabalhado e, por isso, não tem sido muito conotado, filosoficamente muito carregado". cf. Vatin, François. Origines historiques d'ergonomie et ergologie. Texte et documents. http://www.ergologie.com/, tradução nossa). 
experimentação, coloca-se como um objeto para as pesquisas de Comunicação, principalmente, no que diz respeito às novas tecnologias $\mathrm{e}$ linguagens, como também às sensibilidades das novas gerações no convívio diário com os suportes midiáticos.

A Ergologia, segundo Rosa (2004), trata a realidade do mundo do trabalho considerando as normas prescritas, porém, indo além delas. As normas prescritas não antecipam de modo pleno o trabalho. Elas são confrontadas no cotidiano das situações reais de trabalho, re-normalizadas pelos sujeitos trabalhadores.

As situações de trabalho implicam em relações de comunicação entre os sujeitos, num diálogo constante com as normas, na efetivação do desempenho da atividade. A Ergologia interessa às pesquisas de comunicação e trabalho, pois permite explicitar a problemática do trabalho como atividade humana requerida em toda e qualquer situação (aí compreendida a situação de trabalho na empresa de comunicação). É em atividade e pela atividade que os sujeitos alinham-se a sistemas de valores - aqui se confrontam a ideologia do cotidiano e as ideologias constituídas (BAKHTIN, 1988) - e fazem escolhas, apropriações e reelaborações dos sentidos que circulam na sociedade. Este referencial teórico é relevante para a compreensão crítica do processo dialético entre o já instituído (normas, leis, conhecimento científico), o investido pelo sujeito como experiência e 0 inédito da atividade sempre específica.

\section{Considerações finais: mais pesquisa}

Os Estudos de Recepção nos permitiram até agora comprovar a relevância das relações interpessoais no mundo do trabalho no processo de comunicação. Pudemos verificar quão as mudanças tecnológicas, de gestão da produção e de pessoas têm preocupado os trabalhadores e interferido em suas relações de comunicação e no conjunto de suas atividades.

Esses resultados chamaram nossa atenção para a realidade das empresas de comunicação e seus profissionais. Daí desenvolvermos pesquisa, cujo objetivo é compreender como as tecnologias e a organização do trabalho nas empresas de comunicação mudaram o perfil da própria empresa e de seus profissionais, alterando, em decorrência, os produtos culturais da mídia e as relações que empresas, profissionais e produtos culturais têm com a sociedade na esfera do consumo, da política, da sociabilidade.

A nossa experiência de pesquisa no campo da comunicação, somada ao aporte teórico da Ergologia, favorece reflexões sobre os processos de recepção. Ambos possibilitam enfrentarmos com maior rigor os desafios teóricos que a composição do binômio Comunicação e Trabalho trouxe para as ciências da comunicação. Acrescentar aos nossos referenciais teóricos 0 aporte da Ergologia nos possibilita avançar 
um território que há algum tempo tentamos compreender: o sujeito e a relevância das relações de comunicação no mundo do trabalho.

Como e por que a comunicação tem possibilitado introduzir tantas mudanças no trabalho, embora não tenha sido reconhecida como elemento chave dessas mudanças. Estas são questões que poderemos responder à medida que aprofundarmos nossos estudos e pesquisas.

\section{Referências}

ANTUNES, Ricardo. Os sentidos do trabalho. São Paulo: Boitempo. 2000.

ARAGÃO, Lucia M. de C. Razão comunicativa e teoria social crítica em Jürgen Habermas. Rio de Janeiro: Tempo Brasileiro, 1997.

BAKHTIN, Mikhail. Marxismo e filosofia da linguagem. São Paulo: Hucitec, 1988.

BOLAÑO, C. R. S. Trabalho intelectual, comunicação e capitalismo: a re-configuração do fator subjetivo na atual reestruturação produtiva. Revista da Sociedade Brasileira de Economia Política. Rio de Janeiro, n. 11, p. 53-78, dez.2002-abr. 2003.

CHANLAT, Jean-François (org.) 0 indivíduo na organização. São Paulo: Atlas, 1996. 3v.

DEFLEUR, Melvin, BALL-ROKEACH, Sandra. Teorias da comunicação de massa. Rio de Janeiro: Jorge Zahar, 1997.

ESCOSTEGUY, Ana C.; JACKS, Nilda. Comunicação \& Recepção. São Paulo: Hacker, 2005.
FAIRCLOUGH, Norman. Discurso e mudança

social. Brasília: UnB, 2001.

FÍGAR0, Roseli. Relações de comunicação no mundo do trabalho. São Paulo: Annablume. 2008. Comunicação e Trabalho. Estudo de recepção: 0 mundo do trabalho como mediação da comunicação. São Paulo: Anita/Fapesp. 2001. . Crítica à ação comunicativa e à razão comunicativa: para entender a comunicação no mundo do trabalho. Epitc - Revista de Economia Política de las Tecnologias de la Informaión Y comunicación, [S.l.], v. VI, n. 2, p.54-64, 2004. (org.). Gestão da comunicação no mundo do trabalho, educação, terceiro setor $\mathbf{e}$ cooperativismo. São Paulo: Atlas. 2005a. 0 desafio teórico-metodológico nas pesquisas de recepção. E-compós - Revista da Associação Nacional dos Programas de PósGraduação em Comunicação, Brasília, v. 3, ago. 2005b. Disponível em: <http://www.compos.org. br/seer/index.php/e-compos/article/view/42/42>. Acesso em: 20 set. 2009.

GRAMSCI, Antônio. Obras escolhidas. São Paulo: Martins Fontes, 1978.

GRAMSCI, Antônio. Escritos políticos. Lisboa: [s.n.], 1977.

HABERMAS, J. Teoría de la acción comunicativa (I e II). Madrid: Taurus, 1999. 
Consciência moral e agir comunicativo.

Rio de Janeiro:Tempo Brasileiro, 1989.

HALL, Stuart. Da diáspora: identidade e mediações culturais. Organização: Liv Sovik. Belo Horizonte/Brasília: UFMG/Hitas/Unesco, 2003.

IANNI, Octávio. Enigmas da modernidade mundo. 3.ed. Rio de Janeiro: Civilização Brasileira, 2003.

LOPES, Maria Immacolata V. de; BORELLI, Sílvia Simões; RESENDE, Vera da Rocha.

Vivendo com a telenovela: mediações, recepção, teleficcionalidade. São Paulo: Summus, 2002.

MARTÍN-BARBERO, Jesús. De los medios a las mediaciones. 3. ed. México: G. Gilli, 1993. . De los medios a las practicas. In: OROZCO-GÓMEZ, Guillermo. La comunicación desde las prácticas sociales: Reflexiones en torno a su investigación. Cuadernos de comunicación y prácticas sociales, México, n.1, 9-18, 1990 .

MORAES, Dênis. (org.) Globalização, mídia e cultura contemporânea. São Paulo: Letra Livre, 1997.

Medios, audiencias y mediaciones.

Comunicar. Revista de Educación en Medios de Comunicación, Andalucía, n. 8, [s.p.], mar. 1997.

\section{PÊCHEUX, Michel. Semântica e discurso:} uma crítica à afirmação do óbvio. Campinas: Edunicamp, 1988.
ROSA, Maria Inês. Trabalho, subjetividade e poder. São Paulo: Edusp, 1994.

Usos de Si e testemunhos de

trabalhadores: com estudo crítico da Sociologia industrial e da reestruturação produtiva. São Paulo: Letras e Letras, 2004.

SCHAFF, Adam. Linguagem e conhecimento.

Coimbra: Almedina, 1976.

0 marxismo e o indivíduo. Rio de Janeiro: Civilização Brasileira, 1967.

SCHWARTZ, Yves. Expérience et connaissance du travail. Paris: Messidor; Éditions sociales, 1988.

Reconnaissance au travail: pour une approche ergologique. Paris: PUFF, 1997.

Discipline episthémique, discipline ergologique : paideia et politeia. In: MAGGI, Bruno. Manière de penser, manière d'agir en éducation et en formation. Paris: Puf, 2000. p. 33-68.

Trabalho e uso de si. Pro-Posições.

Revista da Faculdade de Educação da UNICAMP, Campinas, v.11, n. 2(32), p. 34-50, jul. 2000.

SOUZA E SILVA, Maria Cecília P.; FAÏTA, Daniel. Linguagem e trabalho: construção de objetos de análise no Brasil e na França. São Paulo: Cortez, 2002.

WOLF, Mauro. Teorias da Comunicação. 2. ed. Lisboa: Presença, 1992. 


\begin{tabular}{|c|c|}
\hline $\begin{array}{l}\text { Reception Study and } \\
\text { Ergology: new theoretical- } \\
\text { methodological challenges }\end{array}$ & $\begin{array}{l}\text { Estudios de Recepción } \\
\text { y Ergología: nuevos desafíos } \\
\text { teórico-metodológicos }\end{array}$ \\
\hline $\begin{array}{l}\text { Abstract } \\
\text { This article discusses the theoretical- } \\
\text { methodological advances of the communication } \\
\text { and work research from the reception studies. } \\
\text { It also discusses the necessity to deepen the } \\
\text { developed research realized until now, taking as } \\
\text { problem the subjectivity and the communication } \\
\text { relations. So, this article proposes to discuss, in } \\
\text { an introductory way, the contributions that it is } \\
\text { possible to reach utilizing the cross-disciplinary } \\
\text { theoretical approach of Ergology. The Ergology } \\
\text { studies work as a human activity that holds } \\
\text { norms and their transformation by means of the } \\
\text { real work. The communication relations have } \\
\text { determinative role in the accomplishment of the } \\
\text { activity of work. } \\
\text { Keywords } \\
\text { Reception studies. Work. Ergology. Discourse. } \\
\text { Communication. }\end{array}$ & $\begin{array}{l}\text { Resumen } \\
\text { Este artículo discute los avances teórico- } \\
\text { metodológicos de la investigación de } \\
\text { comunicación y el trabajo aportado en los estudios } \\
\text { de recepción. También discute la necesidad de } \\
\text { profundizar la investigación desarrollada hasta } \\
\text { ahora, teniendo como problema la subjetividad } \\
\text { y las relaciones de comunicación. Por lo tanto, } \\
\text { este artículo se propone a discutir, de manera } \\
\text { preliminar, las contribuciones a las que se puede } \\
\text { llegar con el enfoque teórico transversales de } \\
\text { Ergología. La Ergología estudia el trabajo como } \\
\text { actividad humana que contiene las prescripciones } \\
\text { de normas y su renormalización por medio del } \\
\text { trabajo real. Las relaciones de comunicación } \\
\text { tienen papel determinante en la efectivación de la } \\
\text { actividad de trabajo. } \\
\text { Palabras clave } \\
\text { Estudios de recepción. Mundo del trabajo. } \\
\text { Ergología. Discurso. Comunicación. }\end{array}$ \\
\hline
\end{tabular}




\section{Expediente}

A revista E-Compós é a publicação científica em formato eletrônico da Associação Nacional dos Programas de Pós-Graduação em Comunicação (Compós). Lançada em 2004, tem como principal finalidade difundir a produção acadêmica de pesquisadores da área de Comunicação, inseridos em instituições do Brasil e do exterior.
E-COMPÓS I www.e-compos.org.br I E-ISSN 1808-2599

Revista da Associação Nacional dos Programas de Pós-Graduação em Comunicação. Brasília, v.12, n.3, set./dez. 2009.

A identificação das edições, a partir de 2008 passa a ser volume anual com três números.

\section{CONSELHO EDITORIAL}

Afonso Albuquerque

Universidade Federal Fluminense, Brasil

Alberto Carlos Augusto Klein

Universidade Estadual de Londrina, Brasi

Alex Fernando Teixeira Primo

Universidade Federal do Rio Grande do Sul, Brasil

Alfredo Vizeu

Universidade Federal de Pernambuco, Brasi

Ana Carolina Damboriarena Escosteguy

Pontifícia Universidade Católica do Rio Grande do Sul, Brasil

Ana Silvia Lopes Davi Médola

Universidade Estadual Paulista, Brasil

André Luiz Martins Lemos

Universidade Federal da Bahia, Brasil

Ângela Freire Prysthon

Universidade Federal de Pernambuco, Brasil

Antônio Fausto Neto

Universidade do Vale do Rio dos Sinos, Brasil

Antonio Carlos Hohlfeldt

Pontifícia Universidade Católica do Rio Grande do Sul, Brasil

Arlindo Ribeiro Machado

Universidade de São Paulo, Brasil

César Geraldo Guimarães

Universidade Federal de Minas Gerais, Brasi

Cristiane Freitas Gutfreind

Pontifícia Universidade Católica do Rio Grande do Sul, Brasil

Denilson Lopes

Universidade Federal do Rio de Janeiro, Brasil

Eduardo Peñuela Cañizal

Universidade Paulista, Brasil

Erick Felinto de Oliveira

Universidade do Estado do Rio de Janeiro, Brasil

Francisco Menezes Martins

Universidade Tuiuti do Paraná, Brasil

Gelson Santana

Universidade Anhembi/Morumbi, Brasil

Goiamérico Felício

Universidade Federal de Goiás, Brasil

Hector Ospina

Universidad de Manizales, Colômbia

Herom Vargas

Universidade Municipal de São Caetano do Sul, Brasil

leda Tucherman

Universidade Federal do Rio de Janeiro, Brasil

Itania Maria Mota Gomes

Universidade Federal da Bahia, Brasil

Janice Caiafa

Universidade Federal do Rio de Janeiro, Brasil

Jeder Silveira Janotti Junior

Universidade Federal da Bahia, Brasil

\section{João Freire Filho}

Universidade Federal do Rio de Janeiro, Brasil

John DH Downing

University of Texas at Austin, Estados Unidos

José Luiz Aidar Prado

Pontifícia Universidade Católica de São Paulo, Brasil

José Luiz Warren Jardim Gomes Braga

Universidade do Vale do Rio dos Sinos, Brasi

Juremir Machado da Silva

Pontifícia Universidade Católica do Rio Grande do Sul, Brasil

Lorraine Leu

University of Bristol, Grã-Bretanha

Luiz Claudio Martino

Universidade de Brasília, Brasil

Maria Immacolata Vassallo de Lopes

Universidade de São Paulo, Brasil

Maria Lucia Santaella

Pontifícia Universidade Católica de São Paulo, Brasil

Mauro Pereira Porto

Tulane University, Estados Unidos

Muniz Sodre de Araujo Cabral

Universidade Federal do Rio de Janeiro, Brasil

Nilda Aparecida Jacks

Universidade Federal do Rio Grande do Sul, Brasil

Paulo Roberto Gibaldi Vaz

Universidade Federal do Rio de Janeiro, Brasil

Renato Cordeiro Gomes

Pontifícia Universidade Católica do Rio de Janeiro, Brasil

Ronaldo George Helal

Universidade do Estado do Rio de Janeiro, Brasil

Rosana de Lima Soares

Universidade de São Paulo, Brasil

Rossana Reguillo

Instituto Tecnológico y de Estudios Superiores do Occidente, México

Rousiley Celi Moreira Maia

Universidade Federal de Minas Gerais, Brasil

Samuel Paiva

Universidade Federal de São Carlos, Brasil

Sebastião Albano

Universidade Federal do Rio Grande do Norte, Brasil

Sebastião Carlos de Morais Squirra

Universidade Metodista de São Paulo, Brasil

Simone Maria Andrade Pereira de Sá

Universidade Federal Fluminense, Brasi

Suzete Venturelli

Universidade de Brasília, Brasil

Valério Cruz Brittos

Universidade do Vale do Rio dos Sinos, Brasil

Veneza Mayora Ronsini

Universidade Federal de Santa Maria, Brasil

Vera Regina Veiga França

Universidade Federal de Minas Gerais, Brasi

\section{COMISSÃO EDITORIAL}

Felipe da Costa Trotta I Universidade Federal de Pernambuco, Brasil Rose Melo Rocha I Escola Superior de Propaganda e Marketing, Brasil

\section{CONSULTORES AD HOC}

Arthur Autran Franco de Sá Neto I Universidade Federal de São Carlos

Carlos Eduardo Franciscato I Universidade Federal de Sergipe

Elisa Reinhardt Piedras I Universidade Federal do Rio Grande do Su

Elizabeth Bastos Duarte I Universidade Federal de Santa Maria

Marcia Benetti Machado I Universidade Federal do Rio Grande do Sul

Sandra Maria Lúcia Pereira Gonçalves I Universidade Federal do Rio Grande do Sul

Suzana Kilpp I Universidade do Vale do Rio dos Sinos

Tattiana Gonçalves Teixeira I Universidade Federal de Santa Catarina

Vander Casaqui I Escola Superior de Propaganda e Marketing

Vicente Gosciola I Universidade Anhembi Morumbi

Walter Teixeira Lima Junior I Fundação Cásper Líbero

REVISÃO DE TEXTO E TRADUÇÃO I Everton Cardoso

EDITORAÇ̃̃ ELETRÔNICA I Raquel Castedo
COMPóS I www.compos.org.br

Associação Nacional dos Programas de Pós-Graduação em Comunicação

Presidente

Itania Maria Mota Gomes

Universidade Federal da Bahia, Brasil

itania@ufba.br

Vice-presidente

Julio Pinto

Pontifícia Universidade Católica de Minas Gerais, Brasil

juliopinto@pucminas.br

Secretária-Geral

Ana Carolina Escosteguy

Pontifícia Universidade Católica do Rio Grande do Sul, Brasil

carolad@pucrs.br 